\title{
Finite element model updating of natural fibre reinforced composite structure in structural dynamics
}

\author{
M.S.M. Sani ${ }^{1,2, a}$, N.A.Z. Abdullah ${ }^{1}$, S.N. Zahari ${ }^{1}$, J.P. Siregar ${ }^{3}$ and M.M. Rahman ${ }^{3}$ \\ ${ }^{1}$ Advanced Structural Integrity and Vibration Research (ASIVR), Faculty of Mechanical Engineering, \\ Universiti Malaysia Pahang, 26600 Pekan, Pahang, Malaysia \\ ${ }^{2}$ Automotive Engineering Centre, Universiti Malaysia Pahang, Malaysia \\ ${ }^{3}$ Faculty of Mechanical Engineering, Universiti Malaysia Pahang, 26600 Pekan, Pahang, Malaysia
}

\begin{abstract}
Model updating is a process of making adjustment of certain parameters of finite element model in order to reduce discrepancy between analytical predictions of finite element (FE) and experimental results. Finite element model updating is considered as an important field of study as practical application of finite element method often shows discrepancy to the test result. The aim of this research is to perform model updating procedure on a composite structure as well as trying improving the presumed geometrical and material properties of tested composite structure in finite element prediction. The composite structure concerned in this study is a plate of reinforced kenaf fiber with epoxy. Modal properties (natural frequency, mode shapes, and damping ratio) of the kenaf fiber structure will be determined using both experimental modal analysis (EMA) and finite element analysis (FEA). In EMA, modal testing will be carried out using impact hammer test while normal mode analysis using FEA will be carried out using MSC. Nastran/Patran software. Correlation of the data will be carried out before optimizing the data from FEA. Several parameters will be considered and selected for the model updating procedure.
\end{abstract}

\section{Introduction}

The extensively use of composite structure across various field such as automotive, aerospace, naval and other high performance engineering application is due to their unique characteristics; light weight, high specific strength and stiffness, easy to fabricate and excellent thermal characteristics. This has aroused many researchers to study various aspect of their structural behaviour. Same with isotropic materials, composite materials also subjected to various type of damage, mostly crack and delamination. These resulting in local changes of stiffness of element thus the dynamic characteristic are modified. Therefore complete understanding of dynamic behaviour for composite structure should be not taken lightly. Dynamic behaviour in terms of natural frequency, damping ratio and mode shapes can be determine via modal analysis process either by numerical or experimental.

Finite element method is used for various type of structural analysis, although it is practical, discrepancy between the prediction results and the experimental result still exist. The reason this discrepancy exists is due to several factors. In order to reduce the discrepancy is by performing model updating procedure on the finite element model. Model updating is a technique of modifying the modeling assumptions and parameters

\footnotetext{
a Corresponding author: mshahrir@ump.edu.my
}

until the correlation of analytical predictions and experimental results satisfies each other in practical requirement.

Abundant number of studies on model updating technique has been performed as model updating is a popular field of study in structural dynamics. Mottershead and Friswell have presented numerous findings and important issues regarding model updating topic [1-12] including topic of parameterization and regularization. Several concerns regarding this topic have been made in order to ensure the updated model has good physical meaning to the real structure and capable to carry out any prediction simulation and producing promising results.

Many approach of model updating procedure have been introduced by various authors in the past. For example, Esfandiari [13] in his study has demonstrated the utilization on frequency response function (FRF) in model updating aside from using the extracted modal data (natural frequencies, damping ratios and mode shapes) from the FRF obtained experimentally. On the other hand, in another study of model updating procedure explain the practice of making adjustment using modal data [14-18]. Although the above investigation examined the various approach of model updating, to the best of author's knowledge, there are quite a number of references in the literature systematically describe the 
procedure of model updating on composite structure focusing on natural fibre. However, the study of model updating that focus on this type of fibre, which is kenaf fibre is quite a few. This was the motivation behind the present study. Accordingly, the present study attempts to demonstrate the finite element model updating procedure on selected composite material which is the kenaf fiber (hibiscus cannabinus, L. family Malvaceae) with different composition. This study will also attempt to improve the presumed geometrical and material properties of tested composite structure that was used beforehand in finite element prediction.

\section{Kenaf fiber reinforced composite structure}

In this investigation, the natural fiber, which is kenaf, was combined with the resin or matrix, which is epoxy, to complete the variation of composite material with different percentage of composition. Hand lay-up process was performed for the preparation of the composite material (Figure 1). The compositions of the composite structures were prepared as follows:

$$
\begin{aligned}
\text { i. } & 5 \% \text { kenaf }+95 \% \text { epoxy } \\
\text { ii. } & 10 \% \text { kenaf }+90 \% \text { epoxy } \\
\text { iii. } & 15 \% \text { kenaf }+85 \% \text { epoxy }
\end{aligned}
$$

To start with, both kenaf and epoxy were weighted using the weighing scales with the correct measurement. Then, kenaf was mixed with the polyester and stirred together to obtain the new composite material. The mixture was poured into glass mold and paint roller was used to consolidate the mixture thoroughly wetting the reinforcement and eliminate the entrapped air. The composite material was left for 24 hours until it became harden before the composite was separated with the mold.

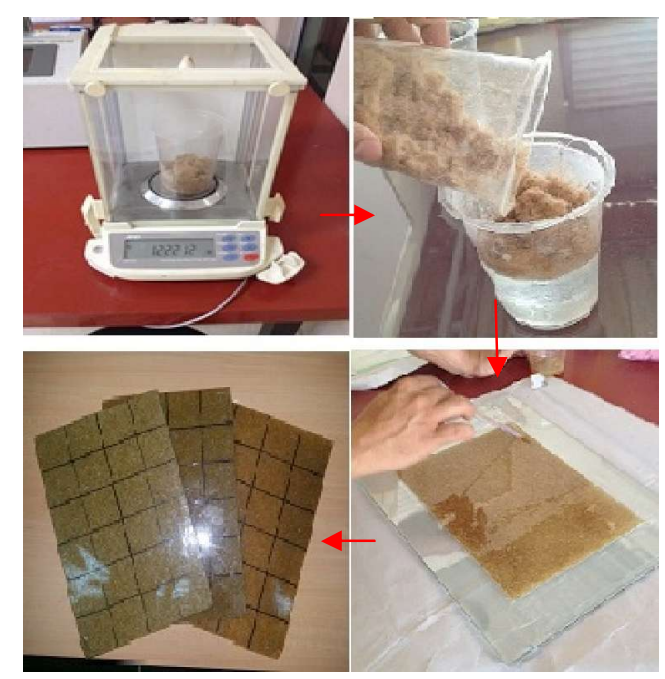

Fig. 1. Full process for preparing the specimen.

\section{Numerical Analysis}

Normal mode analysis was performed on the finite element (FE) model of composite plate via MSC Nastran software to obtain modal data of the composite plate structure for each composition. The FE model of all the composite plates ware modelled using four-node shell elements (CQUAD4) built in MSC Patran software. The composite plates consist of 24 element and 35 nodes. The geometrical and material properties as stated in Table 1 were assigned to the FE model of the composite structure. The value of Young's Modulus of the composite with each composition, were obtained and calculated based on the tensile test carried out on other specimen of the same composition of kenaf fibres. The free-free boundary condition was applied to the structure. Then, normal mode analysis (SOL 103) was executed to compute modal data of the composite structure. The first five natural frequencies obtained throughout the FE analysis are shown in Table 2. The density of the composites plates for each composition was calculated based on general rule of mixture formula for density (refer to Equation 1).

$\rho_{c}=\rho_{f} v_{f}+\rho_{m} v_{m}$

where $\rho_{c}, \rho_{f}$ and $\rho_{m}$ is the density of the composite, fiber and matrix respectively while $v_{f}$ and $v_{m}$ is the volume percentage of fiber and matrix respectively.

Table 1. Assigned geometrical and material properties of the composite plate structure.

\begin{tabular}{|c|c|c|c|}
\hline \multirow{2}{*}{ Properties } & \multicolumn{3}{|c|}{$\begin{array}{c}\text { Value according to kenaf } \\
\text { composition }\end{array}$} \\
\cline { 2 - 4 } & $\mathbf{5 \%}$ & $\mathbf{1 0 \%}$ & $\mathbf{1 5 \%}$ \\
\hline Young's Modulus $(\mathrm{GPa})$ & 1.55 & 1.7 & 1.8 \\
\hline Density $\left(\mathrm{kg} / \mathrm{m}^{3}\right)$ & 1390 & 1380 & 1370 \\
\hline Poisson Ratio & 0.291 & 0.291 & 0.291 \\
\hline Thickness $(\mathrm{m})$ & 0.003 & 0.003 & 0.003 \\
\hline
\end{tabular}

\section{Experimental Modal Analyses (EMA)}

Modal testing or EMA was used to extract modal parameters of the composite structures experimentally. Impact hammer test was used as the excitation method in this EMA. All the composite plate was divided into 24 grids point to represent the point where FRF will be measured. A tri-axial accelerometer was used to measure the acceleration of the structures when external force was applied to them by using impact hammer. The composite plates were supported by elastic sponge during testing in order to simulate the free-free boundary condition as assigned in numerical analysis.

DasyLab software was used in order to measure the input signal from the impact hammer and the acceleration of the plates from the accelerometer. All the signals were converted into frequency response function (FRF) which was later processed in post-processing software in order to obtain modal data of all tested composite plates. The modal data obtained were correlated with the modal data that was gathered previously using finite element analysis (FEA) so as to ensure that the selected modes were paired correctly. Comparison of natural frequencies obtained experimentally and through FEA was shown in Table 2 . Based on the table, it is apparent that there are significant 
value of error between data gathered through EMA and FEA. The presupposition that can be done regarding this matter is that presume properties used for the composite structure in FEA was inexact.

\section{Model Updating}

Model updating, as stated in previously in this paper, is an effective method that can be used to improve correlation between finite element model and experimental results. This can be done by changing the modelling parameters that have been assigned beforehand as an assumption value. By using data gathered through experiment, the assumption that was assigned can be corrected into more accurate value. Therefore, more precise numerical model with more trusted properties can be computed.

The optimization algorithm built in MSC Nastran was used. The objective function, J, which was used for error minimization in the updating process, is stated in Equation 2. The prediction of the modal data was put for error reduction in this updating procedure. The operation was carried out until convergence was achieved when the error function between two data was small enough.

$$
J=\sum^{n} j_{=1}\left(\lambda_{j} / \lambda_{j}^{\exp }-1\right)^{2}
$$

As shown in Equation $1, \lambda_{j}$ is the $j$ th prediction of eigenvalue from FE model while $\lambda_{j}{ }^{\exp }$ is the jth eigenvalue prediction obtained experimentally. It is prominent that this equation is only considered as valid for use if the experimental eigenvalue and analytical eigenvalues are paired correctly. Comparison of natural frequencies values of initial $\mathrm{FE}$ results and the model updating results is given in Table 2 as well. As shown in the table, significant difference exists between natural frequency value before and after model updating was performed. Percentage of errors of data before updating and post updating are also lessening satisfactorily.

On the other hand, sensitivity analysis was done in order to select the updating parameters to ensure that only sensitive or significant parameters are chosen for model updating [16]. Formulation of sensitivity analysis is shown as follows:

$$
\begin{aligned}
& \omega^{2}{ }_{n+1}=\omega^{2}{ }_{n}+S_{i}(\delta \theta) \\
& S_{i}=\delta \omega^{2} / \delta \theta=u_{i}^{T}\left(\delta K / \delta \theta-\omega^{2} \delta M / \delta \theta\right) u_{i}
\end{aligned}
$$

In Equation 3, $S_{i}$ is a sensitivity matrix at $i$ th iteration, which represents the rates of change of the structural eigenvalues $\omega^{2}$ with respect to changes in parameter $\delta \theta$, which can be expressed as in Equation 4.

Two parameters that were picked for this study are the Young's modulus of the kenaf and epoxy composite and the thickness of the composite plate structure. The value of Young's modulus was allowed to vary from $1.549 \mathrm{GPa}$ to $2.184 \mathrm{GPa}$ for plate of $5 \%$ kenaf composition, 1.69 $\mathrm{GPa}$ to $2.184 \mathrm{GPa}$ for plate of $10 \%$ kenaf composition, and $1.79 \mathrm{GPa}$ to $2.184 \mathrm{GPa}$ for plate of $15 \%$ kenaf composition which are the range value of the composite material with the tested composition [17]. At the same time, the thickness value was allowed to vary in small range from its initial presumes value since the thickness of the composite plate can hardly diverse much all over the plate structure due to its slight unevenness on lower surface.In addition, by performing the sensitivity analysis [18-20] on the selected parameters, the actual properties of the composite structure can be computed and the presumed value of the composite was corrected. Table 3 shows the changes of the updated parameter properties

\begin{tabular}{|c|c|c|c|c|c|c|c|c|c|c|c|c|c|c|c|}
\hline \multirow{3}{*}{ Mode } & \multirow{2}{*}{\multicolumn{3}{|c|}{$\begin{array}{l}\text { EMA natural } \\
\text { frequency }(\mathrm{Hz})\end{array}$}} & \multicolumn{6}{|c|}{ Initial FE results } & \multicolumn{6}{|c|}{ Model updating FE results } \\
\hline & & & & \multicolumn{3}{|c|}{$\begin{array}{c}\text { Natural frequency } \\
(\mathrm{Hz})\end{array}$} & \multicolumn{3}{|c|}{ Error (\%) } & \multicolumn{3}{|c|}{ Frequency $(\mathrm{Hz})$} & \multicolumn{3}{|c|}{ Error (\%) } \\
\hline & $\begin{array}{c}5 \% \\
\text { kenaf }\end{array}$ & $\begin{array}{l}10 \% \\
\text { kenaf }\end{array}$ & $\begin{array}{l}15 \% \\
\text { kenaf }\end{array}$ & $\begin{array}{c}5 \% \\
\text { kenaf }\end{array}$ & $\begin{array}{c}10 \% \\
\text { kenaf }\end{array}$ & $\begin{array}{l}15 \% \\
\text { kenaf }\end{array}$ & $\begin{array}{c}5 \% \\
\text { kenaf }\end{array}$ & $\begin{array}{l}10 \% \\
\text { kenaf }\end{array}$ & $\begin{array}{l}15 \% \\
\text { kenaf }\end{array}$ & $\begin{array}{c}5 \% \\
\text { kenaf }\end{array}$ & $\begin{array}{l}10 \% \\
\text { kenaf }\end{array}$ & $\begin{array}{l}15 \% \\
\text { kenaf }\end{array}$ & $\begin{array}{c}5 \% \\
\text { kenaf }\end{array}$ & $\begin{array}{l}10 \% \\
\text { kenaf }\end{array}$ & $\begin{array}{l}15 \% \\
\text { kenaf }\end{array}$ \\
\hline 1 & 37.0 & 38.9 & 39.3 & 33.98 & 35.72 & 36.89 & 8.16 & 8.17 & 6.13 & 37.72 & 38.56 & 38.55 & 1.95 & 0.87 & 1.91 \\
\hline 2 & 40.4 & 42.0 & 44.0 & 38.18 & 40.13 & 41.45 & 5.50 & 4.45 & 5.80 & 42.39 & 43.33 & 43.32 & 4.93 & 3.17 & 1.55 \\
\hline 3 & 87.1 & 89.4 & 90.3 & 71.91 & 75.58 & 78.06 & 17.44 & 15.46 & 13.55 & 79.84 & 81.61 & 81.58 & 8.34 & 8.71 & 9.66 \\
\hline 4 & 90.3 & 92.7 & 93.0 & 75.29 & 79.13 & 81.72 & 16.62 & 14.64 & 12.13 & 83.56 & 85.42 & 85.39 & 7.46 & 7.85 & 8.18 \\
\hline 5 & 101.0 & 104.0 & 107.0 & 87.92 & 92.40 & 95.43 & 12.95 & 11.15 & 10.81 & 97.58 & 99.75 & 99.71 & 3.39 & 4.09 & 6.81 \\
\hline
\end{tabular}
from their initial values.

Table 2. Comparison of natural frequency values between initial results and updated results.

Table 3. Change of updated parameter properties from their initial values.

\begin{tabular}{|c|c|c|c|c|}
\hline Parameter & Kenaf composition & Initial value (I) & Updated value (II) & Change (\%) $\mid$ (II-I)/I $\mid$ \\
\hline \multirow{3}{*}{ Young's modulus, E (GPa) } & $5 \%$ & 1.55 & 1.76 & 13.55 \\
\cline { 2 - 5 } & $10 \%$ & 1.70 & 1.83 & 7.65 \\
\cline { 2 - 5 } & $15 \%$ & 1.80 & 1.87 & 3.89 \\
\hline \multirow{2}{*}{ Thickness, t (m) } & $5 \%$ & 0.0030 & 0.0031 & 3.33 \\
\cline { 2 - 5 } & $10 \%$ & 0.0030 & 0.0031 & 3.33 \\
\hline
\end{tabular}




\begin{tabular}{|l|l|c|c|c|}
\hline & $15 \%$ & 0.0030 & 0.0031 & 3.33 \\
\hline
\end{tabular}

\section{Conclusions}

This study was carried out in order to perform modal based model updating on composite structure as well as to improve the presumed geometrical and material properties of the tested composite structure in FE prediction. The updating procedure is observed as parameter identification, which intends to bring the finite element prediction to be as closely as possible to the actual test subject.

The initial FE prediction of the composite plate has shown quite diversion from the experimental findings, mostly caused by uncertain value of properties assigned on the structure. However, the uncertain properties values have successfully improved after updating procedure. Furthermore, the percentage of error for those two sets of data (FE and experiments) reduced satisfactory after updating. The most sensitive parameters for updating the composite plate also have been identified as well as computing the updated value for each of the updating parameters. Obviously, the updated value for those parameters showed dissimilarity when compared to the values that was assigned initially on the structure in FE.

The evidence from this study testifies that model updating technique or also called model calibration is proven to be a good method in reducing divergences. Concurrently, SOL200 is proven to be an effective algorithm for finding the sensitivity of parameters. More information on model updating technique would help us to establish a greater degree of accuracy on this matter. If the investigation is to be moved forward, a better understanding of model updating technique and parameterization needs to be developed.

\section{Acknowledgement}

The authors would like to express their gratitude to the Malaysia Ministry of Higher Education (MOHE) for providing the FRGS fund for this study.

\section{References}

1. H. Ahmadian, J. E. Mottershead, and M. I. Friswell, "Physical Realization of Generic-Element Parameters in Model Updating," Journal of Vibration and Acoustics, vol. 124. p. 628, (2002)

2. H. H. Khodaparast, J. E. Mottershead, and K. J. Badcock, "Interval model updating with irreducible uncertainty using the Kriging predictor," Mech. Syst. Signal Process., vol. 25, no. 4, pp. 1204-1226, (May 2011)

3. M. Palmonella, M. I. Friswell, J. E. Mottershead, and A. W. Lees, "Finite element models of spot welds in structural dynamics: Review and updating," Computers and Structures, vol. 83. pp. 648-661, (2005)

4. J. E. Mottershead, M. I. Friswell, G. H. T. Ng, and J. A. Brandon, "Geometric Parameters for Finite
Mech. Syst. Signal Process., vol. 10, pp. 171-182,
Mement Modraints," (1996)

5. J. E. Mottershead, M. Link, and M. I. Friswell, "The sensitivity method in finite element model updating: A tutorial," Mech. Syst. Signal Process., vol. 25, no. 7, pp. 2275-2296, (Oct. 2011)

6. J. E. Mottershead and M. I. Friswell, "Model Updating In Structural Dynamics: A Survey," J. Sound Vib., vol. 167, pp. 347-375, (1993)

7. W. Wang, J. E. Mottershead, C. M. Sebastian, and E. A. Patterson, "Shape features and finite element model updating from full-field strain data," Int. J. Solids Struct., vol. 48, no. 11-12, pp. 1644-1657, (Jun. 2011)

8. C. Mares, M. I. Friswell, and J. E. Mottershead, "Model updating using robust estimation," Mech. Syst. Signal Process., vol. 16, no. 1, pp. 169-183, (Jan. 2002)

9. M. I. Friswell and J. E. Mottershead, Finite element model updating in structural dynamics, vol. 38 . (1995)

10. M. I. Friswell, J. E. Mottershead, and H. Ahmadian, "Finite-element model updating using experimental test data: parametrization and regularization," Philos. Trans. R. Soc. London, Ser. A (Mathematical, Phys. Eng. Sci., vol. 359, pp. 169-186,(2001)

11. C. Mares, J. E. Mottershead, and M. I. Friswell, "Natural-Frequency Errors and Using Physical Reasoning," J. Vib. Acoust., vol. 17, no. 1, pp. 3946, (Jan. 2003)

12. W. Wang, J. E. Mottershead, A. Ihle, T. Siebert, and H. Reinhard Schubach, "Finite element model updating from full-field vibration measurement using digital image correlation," J. Sound Vib., vol. 330, no. 8, pp. 1599-1620, (Apr. 2011)

13. A. Esfandiari, F. Bakhtiari-Nejad, M. Sanayei, and A. Rahai, "Structural finite element model updating using transfer function data," Comput. Struct., vol. 88, no. 1-2, pp. 54-64, (Jan. 2010)

14. H.-P. Chen and T. S. Maung, "Regularised finit e element model updating using measured incomplete modal data," J. Sound Vib., vol. 333, no. 21, pp. 5566-5582, (Oct. 2014)

15. E. Jacquelin, S. Adhikari, and M. I. Friswell, "A second-moment approach for direct probabilistic model updating in structural dynamics," Mech. Syst. Signal Process., vol. 29, pp. 262-283, May 2012.

16. N. Husain and A. Snaylam, "FE Model Updating for Damage Detection-Application to a Welded Structure," Key Eng. ..., vol. 414, no. 2009, (2009)

17. R. Bow and M. Selection, "The Investigation of Mechanical Properties on Natural Fiber Composites for Recurve Bow Material Selection," vol. 9, no. 25, pp. 27-31, (2015)

18. N. Abdullah, et al. A review on model updating in structural dynamics. in IOP Conference Series: Materials Science and Engineering. vol. 10001 (2015) doi:10.1088/1757-899X/100/1/012015 